\title{
Effect of Employee Engagement on Performance of Small and Medium Size Enterprises in Mombasa County, Kenya
}

\author{
Mary Peninah Ibua \\ Department of Management Science, Technical University of Mombasa, P.O. Box 90420-80100, \\ Mombasa, Kenya \\ Email: peninahmary@gmail.com or mibua@tum.ac.ke
}

\begin{abstract}
$\mathrm{I}$ $\mathrm{n}$ today's global environment one of the major challenges is having engaged workforce in an organization. The workforce is one of the organization's greatest assets. Employee engagement is the process of keeping employees engaged in the organization. It is one of the key fundamentals of making an organization competitive. The main objective of this study was to investigate the effect of employee engagement on performance of small and medium organizations in Mombasa County, Kenya. A positivist paradigm using descriptive research design was used. Stratified random sampling technique was used to interview respondents. The study sampled a total of 105 small and medium enterprises operators. A questionnaire with Likert-type interval scale anchored on a 5-point scale was used to collect data. Hypotheses were tested using Pearson's product moment and multiple regression. Findings of the study indicated that most of the small and medium enterprises (SMEs) have not embraced the concept of employee engagement. Nonetheless they have awareness of the practices that employees desired which would give them competitive edge. It is of necessity that the SMEs operators be trained on best practices and also benchmark within their industry subsectors so as to be able to initiate and embrace employee engagement. At start-ups and early stages of business growth, there is minimal investment in human resources which results in haphazard recruitment of family members who are sometimes are neither qualified nor trained and not engaged. Consequently, the staff underperforms, a lot of infighting and conflicts in families and relatives, leading to strained family relationships and high labour turnover which in turn affects performance. The study recommended a deliberate action be taken by the management to embrace employee engagement concept for their organizations to be competitive. Implications of the study are that adopting employee engagement empowers employees which results in increased performance in organizations. The study also contributes to the literature that seeks to develop theory emphasizing the importance of embracing employee engagement notion as an important human resource concept.
\end{abstract}

Key Words: Employee engagement, Small and Medium Enterprises, Performance, Mombasa County, Kenya

\section{Introduction}

Employee engagement has effect on performance of organizations and increased engagement drives organizations' results. Employee engagement is critical for organizations because employees are the driving force to achievement of organization's performance. Gallup, (2015) posits that there is increased productivity by about $20 \%$ when the workforce is engaged. This author further reports that about $30 \%$ of American workers are engaged and globally only $13 \%$ of workers are engaged in their jobs. This is driving organizations to make employee engagement an area of interest. Employee engagement differentiates one organization from the other, giving the organization with engaged employees a competitive advantage. Organizations with engaged employees outperform their others, and have $51 \%$ higher productivity compared to disengaged employees (Bishop \& Crooks, 2019). Engagement is a key differentiator when it comes to growth and innovation. This makes employee engagement a very important and critical issue in organizations and this needs to be nurtured, shaped and not assumed. Engaged workers are full of energy, enthusiasm, are in control and feel attached to the organization devoid of burnout. They identify themselves with the organizations' vision and mission.

Employee engagement is defined as the extent to which employees commit to something and how long they stay as a result of that commitment. It is built on trust, information sharing and 
commitment (Bishop \& Crooks, 2019). It is also making changes in the workplace so that employees can do their best. Additionally, employee engagement is the extent to which employees feel passionate about their jobs, are committed to the organization, and put discretionary effort into their work (Hassan \& Shoaib, 2014). Engagement starts at the very first stage of recruitment process and it is a never ending process up to retirement. It is a collaborative effort between managers and the workforce. Managers have a powerful effect on how engaged the workforce will be. Engaged employees are emotionally attached to their organizations and are involved in the operations of it. Managers must therefore, create environments that foster employee engagement. For Kenya to grow to an industrialized country according to the Vision 2030 and the Big Four Agenda development strategy, organizations and more so the Small and Medium Enterprises (SMEs) must embrace employee engagement initiatives. In Kenya, SMEs contribute over $30 \%$ to the GDP and creates employment (African Review of Business \& Technology, 2014).

In SMEs, employee engagement is not a very popular topic and normally assumed, and it is seen as an issue of large corporates or a distraction. Nevertheless the size of the organization does not matter if employees feel connected to their jobs, they will always perform beyond their normal duties and excel in what they are doing, and this in turn increases performance of the organization. In view of the challenges SMEs face, it is important that they employ whatever initiatives possible to drive growth and competitiveness in order to succeed and survive in this competitive environment.

Armstrong (2013) and Sendawulo et al. (2015) indicate that an efficient, motivated and skilled workforce is a catalyst for positive change. Having a high degree of employee engagement gives organizations more opportunities to grow and thrive. Employee engagement involves building a workplace environment where involved employees from the lowest cadre to supervisors and managers are allowed to produce their best each day. In the recent past researchers argue that there is employee disengagement. According to Gallup, (2015) only 15\% of employees are engaged in their jobs leaving an estimated $85 \%$ disengaged. Further only $12 \%$ of organizations are satisfied with the level of employee engagement they currently experience. Organizations that have their employees engaged experience about $16 \%$ greater profitability as well as $37 \%$ lower absenteeism (Gallup, 2015). These organizations also report 65\% reduction in employee turnover. Sendawulo et al., (2018), concurs that indeed employee engagement is a great predictor of organization performance, hence an important area to explore. Wilson, (2010) also indicates that disengaged workers are a liability to the organization for they affect productivity of the firm, causes unnecessary costs, and give low quality service.

Notwithstanding the importance of engaging employees, the issue has not been clearly addressed in SMEs. The issue of whether employee engagement practices in large organizations are same as SMEs is also still debatable. Nevertheless Armstrong (2013) posit that human resource is a source of competitive advantage rather than a cost. Employees who are committed to the organization will perform to achieve organization goals and meet customer demands. Most of the studies on employee engagement have been done in developed countries and in large corporates. In sub-Saharan Africa very few studies have been carried out. The SMEs have lagged behind and the few studies done on SMEs have focused more on financial issues dealing with returns and earnings, marketing or operations and management of the business. Little effort has been put on non-financial factors like employee engagement or human resources practices as a whole. SMEs are generally perceived as having few resources to invest in human resources or motivating employees, at the same time few have carried out surveys to check workers level of engagement or satisfaction despite the dynamic environment they are operating in. There is need to find out level of employee engagement in these organization for it is an important area in the management of the enterprises. Therefore, the current study attempts to bridge the gap in knowledge by exploring the level of critical factors of employee engagement which affect SMEs performance in Mombasa County, Kenya.

\section{Small and Medium Enterprises in Kenya}

Small and Medium Enterprises (SMEs) are defined within the context of where they operate, as definitions vary from region to region. SMEs in Kenya continue to grow the economy. According to African Review of Business \& Technology (2017), Kenya's overall GDP was grew by $6.5 \%$ and $3 \%$ was a contribution by SMEs. Further the National Economic Survey (2017), indicate that SMEs constitute $98 \%$ of all business in Kenya and translate to $3 \%$ job creation. In Kenya SMEs fall 
under informal sector. The small and medium firms are found mainly in the main cities and towns across all the counties. The Kenya SME Act 2012 states that micro enterprises are those with a turnover of about USD 5,000 and employ about 10 or less people. In Africa, small enterprises have between USD 5,000 and USD 50,000 with 10-50 employees. However medium size organizations are not covered in the Act with a turnover of between USD 5,000 to USD 8 million with 50-99 employees. The Kenya National Bureau of Statistics (2016) revealed that $16 \%$ of Kenya SMEs are in the cities of Nairobi, Mombasa and Nakuru. Most of the businesses are in buying and selling (retail and wholesale), agriculture, manufacturing, construction, and other service providers like salons, hotels, restaurants, health clinics which make up about $16 \%$. However, SMEs operate in all areas of the economy in Kenya.

Despite the growth and contribution of SMEs majority are the ones which start and do not make it to their second birthday. In Mombasa, about 500 businesses started and failed in 2017 alone (African Review, 2017) due to one reason or another for instance lack of skills, competition, capital, tough economic environment. Further according to Kenya National Bureau of Statistics (2016), there is about 400,000 SMEs that did not celebrate their second birthday. Few reach their fifth birthday leading to concerns of sustainability. As a consequence, exit rate seems to exceed entry rate. In Mombasa County, a major seaport for East Africa, there are increasing businesses registered each year. Currently there are about 41,900 licensed SMEs (Kenya National Bureau of Statistics, 2016), in the same breath few also reach their second birthday.

\section{Theoretical Foundation of the Study}

Guest (2013) and Truss et al. (2013) have explored the issue of employee engagement and its application and concluded that engaged workforce lead to better performance. Engagement is a driving force in business especially in today's uncertain environment. The economic climate in Kenya propagates that organizations should rationalize and have continuous improvement in order to be sustainable. However, to be competitive SMEs have to make a deliberate effort to encourage employee engagement as a strategic tool in order to be successful.

Engagement measures how employees feel about the management and the organization. The definition of engagement has varied considerably over the years and the concept borrows heavily from psychology and social psychology. The term was first introduced by Kahn, (1990) while studying psychological conditions of personal engagement and disengagement at work. This author defined personal engagement as a job expression of individuals in favoring the generating of the relationship between the job, other individuals and themselves and performance. The model emphasized that people expressed themselves cognitively, physically and emotionally. To engage fully you have to see the work as meaningful, safe and fulfilling psychologically. Truss et al. (2013) stated that engagement is the extent which people express themselves through physical involvement, cognitive awareness and emotional conditions. The authors further contented that disengaged employees "remove" themselves from their roles suppressing personal involvement physically and emotionally. Khan (1990) argued that engagement experience is psychological and beneficial to the individual. Guest, (2014) further stated that engagement is associated with satisfaction. The concept here being used to include a host of workrelated attitudes, involvement and job satisfaction. Quantitative research suggest that high levels of engagement lead to high level performance, wellbeing and citizenship behavior (Saone, 2013). This view is supported by Schaufeli (2013) who contend that engagement is a distinct concept which is defined as a fulfilling, positive, and work-related state of mind and is characterized by vigor, enthusiasm and involvement at work. It is that emotional attachment to the job, colleagues and the organization. Fazna \& Zubair (2016) proposes that employee engagement is a positive attitude held by an employee towards the organization and its values. Management has to nurture engagement for it to promote commitment and organization citizenship behavior.

Notwithstanding the above, studies have also shown that some workers are not fully engaged. Wilson (2010) reviewed a survey carried out by Sibson Consulting Firm (USA) and found that satisfaction scores dropped by $50 \%$ and about $65 \%$ of the respondents stated that they were engaged. This lack of engagement affects productivity and leads to customer dissatisfaction. Ayers (2006) argues that if an organization has only 35\% engaged employees then between $50 \%$ and $70 \%$ payroll is ineffective. Gallups (2015) also confirmed that $54 \%$ of workers were not engaged and $17 \%$ disengaged. The disengaged employees just use up

Published: May 2021 
resources and also work against organizations best interest. The underpinning theories in the current study were Resource-Based View Theory and Hertzberg Theory of Motivation.

\section{Resource-Based View Theory}

Resource-Based View Theory (RBV) postulates that the organizations' resources are both tangible and intangible in nature and are rare, valuable, nonsubstitutable, and inimitable (Barney, 1991). This theory views organizations as a collection of resources that are heterogeneously distributed within and across industries. Distinctively, what makes performance of an organization unique are the resources it possesses. Resource based theory emphasizes that there is need to embrace a specific human resource strategy for competitive advantage. This strategy should lead towards a strategic fit of human resource management (HRM) strategies and firm's strategies. This means that the HR practices should be internally consistent and they should complement each other in achieving organization's goals. Drawing from HRM literature and human capital theory, HR practices increases the likelihood of shared vision and goals leading to easier achievement of the organizational objectives.

According to RBV theory, organizations achieve superior performance and access critical resources which are because of their distinctive competencies; one the distinctive competence is employee engagement. Barney (1991) contends that human resource can provide a source of sustained competitive advantage when 4 basic requirements are met. First, they must add value to the organization. Second, the skills must be rare and the third, requirement is that the firms' most important asset the employees must not be easily imitable. Fourthly, firms' human resources should not be substitutable (Pfeffer, 1998). Employee engagement influences acquisition and development of human capital. In the world today there is transition from the production economy to knowledge economy, hence there is a shift on the way we view assets. According to Mahoney \& Kor (2015) the intangible abilities and skills of the workforce and their knowledge contribute a lot towards achievement of the organizations' goals. As such organizations must embrace practices that will engage the workforce to be committed to the organization.

\section{Hertzberg Theory of Motivation}

Herzberg, (2003) believed that the two dimensions of job satisfaction are dissatisfiers (he called them "hygiene" issues) and satisfiers, also called motivators. His theory was that employees can be retained through minimizing dissatisfaction and maximizing satisfaction. Dissatisfies include factors such as administration, company policy, working conditions, supervision, relationships and salary. Satisfiers include the job, promotion, achievement, responsibility and recognition.

Motivator factors include responsible work, independence in doing the work, and satisfaction arising from the completion of challenging tasks. Hygiene factors include pay, security, and general working conditions. According to Herzberg (2003), hygiene factor operates primarily as de-motivators if they are not sufficient. The author suggested that workers are most satisfied and most productive when their jobs are rich in the motivator factor.

Hackman \& Oldham (1976) in their model of job enrichment propose that jobs can be made more motivating by increasing: skill variety, task identity, task significance, autonomy, and feedback. Many of these similar characteristics of the work, particularly independence and competence, are referred to as intrinsic motivators by social psychologists and personality psychologists. Amoatemaa \& Kyeremeh (2016) proposed that intrinsic motivation occurs when individuals feel both self-determined and competent in their work. According to these authors, people will feel competent if they obtain feedback that indicates progress in their work, or suggests ways they can increase their competence. This increases their motivation and hence performance. One psychological view suggests that very high levels of intrinsic motivation are marked by such strong interest and involvement in the work, and by such a perfect match of task complexity with skill level, that people experience some kind of psychological "flow," a sense of merging with the activity they are doing (Armstrong, 2010).

\section{Conceptual Framework}

Conceptual framework is the representative of the variables of interest in the study and their relationship (Kombo \& Tromp, 2009). It shows the general idea inferred or derived from instances in this case, the relationship between human resource practices and organization's performance of SMEs (Fig. 1). 


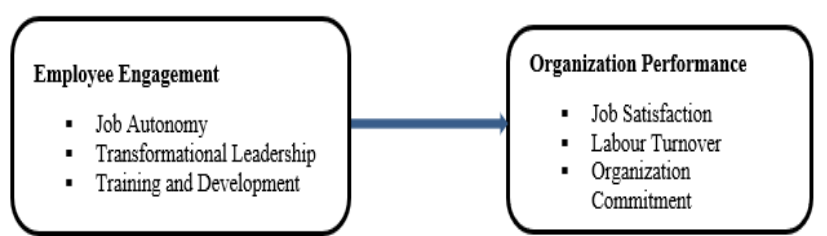

Figure 1. Conceptual model representing the relationship between human resource practices and organization's performance

\section{Job Autonomy}

Job autonomy has been related to higher productivity, involvement and reduced stress. Autonomy makes people act from their convictions. This was first introduced by Hackman \& Oldham, (1976). Job autonomy is the degree to which a job provides substantial freedom and discretion to scheduling work and determining the procedures on how it will be done. According to Hackman \& Oldham, (1976), autonomy leads to high psychological state experienced responsibility for outcomes of work. Further, these author state that autonomy leads to higher performance. Job autonomy can be defined as that practice that gives employees increased decision making authority in respect to their jobs. This perspective views autonomy as structural empowerment (Kanter, 1997). According to Hertzberg Theory of motivation of hygiene factors, job autonomy is a factor that motivates employees. Motivated employees are associated with increased performance and job satisfaction (Armstrong, 2013). Autonomy is viewed as one of the tasks in the Job Characteristic Model; others include task variety, task identity, task significance, autonomy and feedback.

Autonomy involves responsibility of outcomes of the work which results to high work efficiency. Akram, et al. (2013) emphasized that autonomy has an impact on work methods and goal setting. Staff who have the freedom to make work decisions can influence work pace and regulate work processes.

Autonomy leads to employee empowerment which in turn increases individual motivation to perform and achieve organizational goals. Further employees feel that their managers have confidence in their capabilities to make the right decisions. Managers who experience high job autonomy work better than those who do not. According to Langfred \& Moye (2004) job autonomy enhances job performance because they perceive themselves as capable more resourceful in performing the tasks. As such, it can be hypothesized that job autonomy has relationship with performance.

\section{$H_{1}$. Job Autonomy is Positively and Significantly Related to Performance of SMES}

\section{Transformational Leadership Style}

Transformational approach is one of the most popular leadership approaches, which has been in the focus of research since the early 1980s. This approach is part of the New Leadership paradigm, which pays great attention to the charismatic and emotional aspects of leadership. This theory was first proposed by Burns (1978), who was studying the behavior of political leaders and the ways they approach the power they have. The fundamentals of Burns' leadership were later improved by Bass \& Avolio (1996), offering components of transformational leadership, known as the Four I's, meaning intellectual stimulation, idealized influence (charisma), individualized consideration and inspirational motivation. Adnan \& Mubarak, (2010) found out that transformational leadership style is positively related to job success and career satisfaction. Furthermore, Lee et al. (2017) indicate that among different dimensions of transformational leadership, only intellectual stimulation is significantly related to team leader job satisfaction. Define transformational leadership as the one which helps increasing employees' concern and strengthening Bass \& Avolio (1995) their level of perception as well as their acceptance of the groups' vision and aims. Transformational leaders facilitate new understandings by increasing or altering awareness of issues. Resultantly, they foster inspiration and excitement in placing extra efforts to achieve common goals (Armstrong, 2010). It is therefore, hypothesized that transformational leadership has relationship with performance.

\section{$H_{2}$. There is a Positive and Significant Relationship between Leadership Style and Performance of SMEs}

\section{Training and Development}

According to Armstrong, (2010) training is an important component in ensuring that employees have the right skills and abilities to succeed in their work. Training and development are practices that vary from employee orientation, job skill and leadership training to professional career development. These practices improve employee job skills and equip them with skills and expertise to perform their jobs. Training and development has been defined as a continuous effort to build and 
develop employee competencies. Employees who are well trained can share their knowledge and skills and help to enhance performance in the organization. Dissatisfaction with lack of training or career development opportunities leads to employee exit or turnover and may result to poor performance. Training and development can serve as enhancer of employee engagement.

Training is often neglected or overlooked by some employers however, with increase in employment related issues in work place and lawsuits, investing in effective training for managers and supervisors and employees can help tackle challenges in the workplace effectively. Additionally, training employees increases productivity and efficiency, rises job satisfaction and increases employee commitment (Armstrong, 2010). Dessler, (2015), Armstrong (2010) and Cole (2002), concur that employee development programs have bigger impact and affect employee retentions and performance. Mondy (2011) and Mozael (2015) show that training and development increase motivation, build morale, and increase commitment. For instance, new employees are engaged by explaining how the new job contributes to the organization's mission during work orientation. Providing training whether technical or non-technical, formal or in-formal such as mentoring, coaching can further influence employee development which leads to increased productivity (Mozael, 2015). Anwar \& Shakur (2015) stated that employees would be more satisfied if they had an opportunity to train and grow their careers. The process of training contains development, design, analysis implementation and evaluation. An effective employer should build employer-employee exchange relationship and create understanding on how the workers' jobs contribute to achieving organization's mission. This way the employee will be engaged right from the beginning and this leads to job satisfaction and performance. Therefore, it can be hypothesized that training and development has relationship with performance.

H3. There is a Positive and Significant Relationship between Training and Development and Performance of SMEs

\section{Organization Performance}

Organization performance is a concern of every firm. Organizational performance can be defined as firms' performance versus goals and objectives. According to Jenatabadi et al. (2015), most organizations' performance in the past years was limited or focused more on financial indicators like return on investment, return on assets and the like more than non-financial measures. However, traditional measures cannot create value for the organization in the current competitive environment where the measures have changed (Kaplan \& Norton, 1993). Currently, there is need for additional measures so as to enable managers to make strategic decisions. New financial measures and especially non-financial measures have increasingly become important in evaluating the performance of organizations. Measures like balance score card, or market value added have been introduced in the organizations. Practitioners have stressed the need to put an increased emphasis on non-financial measures in the performance measurement process. Organizations are defined from such concepts as productivity, efficiency, effectiveness, competitiveness, profitability. This study uses non-financial measures of job satisfaction, employee turnover and customer satisfaction to measure performance in SMEs.

\section{Job Satisfaction}

Job satisfaction refers to employee's emotional state regarding the job in view of what they expect from the job (Robbins, 2003). Weiss (2002) defines job satisfaction as feelings of contentment derived from the appraisals of one's job. Positive and favorable attitudes towards a job indicate job satisfaction. Negative attitudes towards a job imply job dissatisfaction. Job satisfaction includes how employees feel about the job and the opportunities for growth and development. Factors such as financial rewards, security, organizational environment, and leadership affect the level of job satisfaction in an organization.

Shantz et al. (2013), Monari (2013) and Ibua (2017) have indicated that satisfied employees tend to be more productive, creative and committed to their work which contributes to increased performance. Satisfied employees tend to stay in their jobs. Other researchers contend that dissatisfied employees tend to separate with the organization, which can sometimes be disastrous given the cost of recruitment. Smith \& McCanger (2004) confirmed that lower job satisfaction affects bottom line, increases rate of absenteeism and work quality and lowers production. Further, job dissatisfaction can lead also to high employee turnover and low motivation which eventually affects organization performance. Currently, one of the major issues in the world of work is employee retention. Human resource practices are important to promote 
functional employee behavior in the organization and increase employee retention.

\section{Employee Turnover}

Employee turnover is the rate at which an organization loses or gains employees. It is the measurement of how long employees tend to stay contrasted against the rate at which they leave (Armstrong, 2013). This author agrees employee turnover is costly in terms of replacement, team dynamics, increased tension and workload, and organization knowledge. However, turnover is not always due to the personality of the manager but due to external challenges the employees are facing. Such challenges may include: economic, social, and cultural conditions. The SMEs have to make internal changes that can minimize the impact on the business. On the other hand research has proven that employees do not leave companies but leave supervisors. Supervisors who are perceived as uncaring and cold tend to make staff dissatisfied hence they leave, but those perceived to be caring and supportive bring out the best from the employees (Smith \& McCanger, 2004).

Lack of job satisfaction, low wages and lack of status can also lead to employee quitting a job however, if employees perceive that they are being treated equitably they are likely not to leave. Further, employees' perceptions of the management, supervisors, support, working environment, growth and compensation have effect on turnover. As such the effectiveness of the human resource practices and the value it places on the employees is of great importance. How well these practices are aligned with the organization culture, and how effectively they are communicated will determine the commitment of employees with their jobs and intention to leave.

\section{Organization Commitment}

Organizational commitment is that willingness to persist on a course of action without change of plan. It can also be defined as a view of an organization's member's psychology towards their attachment to the organization that one is working for. According to Vance (2006), organizational commitment plays a pivotal role in determining whether an employee will stay with the organization for a longer period of time and work passionately towards achieving the organization's goal. Commitment manifests itself in distinct behavior; has an emotional component where people experience and express positive feelings towards an entity to whom they have commitment. Commitment has also rational element where people consciously decide to make commitments, then they plan to carry them out. Employers and workers have an agreement whereby if employees are committed they get rewarded for it, but when it fails it breaks the commitment.

Allen \& Meyer (1990) stated that there are 3 levels of commitment. The first level is affective commitment which relates to how much the employee want to stay. It is an emotional attachment towards the organization. The workers identify with the organization and are satisfied with their work. The second level is normative commitment which relates to how much the employees feel they want to stay. The employees who have normative commitment feel that leaving the organization would be disastrous, they feel obligated to stay. The third level is continuance commitment relates to how much they feel they need to stay at their organization. The employee who is continuance committed feels their need to stay probably due to lack of alternatives or the remuneration is good and leaving the organization would be costly. However if the employee is engaged right from the beginning then the level of commitment might increase.

\section{Study Methodology}

This study adopts a descriptive cross-section survey research design in order to explore effects of human resource practices in SMEs. Cooper \& Schindler, (2008) posits that the design allows the collection of a large amount of data from a sizeable population in an economical manner. This method was suitable for SMEs that are scattered in different zones in Mombasa County. According to Cooper \& Schindler (2008) cross-section research design determines reports the way things are at a given time. The design was appropriate for the study because it allowed for generalization of information related to the target population. Stratified random sampling was used. The sample size was 105 representing all sectors of SMEs in Mombasa County. The respondents were picked randomly from various sectors. Data was collected using a questionnaire. The questionnaire was divided into three sections. A 5-point Likert-type scale was used. Respondents had to choose one of the range from strongly agree to strongly disagree. Pearson' Correlation Analysis was used to test the relationship between variables in the study hypothesis while regression analysis was used to determine the statistical relationship between the independent and dependent variables. 


\section{Results}

Data were coded and analyzed using Statistical Package for Social Scientists (SPSS) version 20 and reliability was checked by use of Cronbach's Alpha. The response rate was about $70 \%$. The profiles of the respondents were presented by gender, age, and level of education. The study found out that majority of the respondents were males at 55.5\% while female made up $42.9 \%$. The results imply that all the genders are almost equally involved in SMEs. Age analysis of the respondents observed that $45 \%$ of respondents were of the age 41 years and above. This implied this is the age where most people are looking for growth and opportunities in their careers. The study also found that majority of the respondents had secondary education $(31.9 \%)$, followed by Bachelors' degree at $(31.1 \%)$, and Masters (7.9\%). These implies that majority of the respondent entrepreneurs had adequate education to understand the questionnaire and respond accordingly. Most of the SMEs were in operation for a period of 6-10 years; this can be associated with experience. It also signifies that at least they were stable to implement employee engagement practices.

Table 1. Pearson's Correlation Analysis for all variables (** Significant at $p<0.01$ and *Significant at $p<0.05$ )

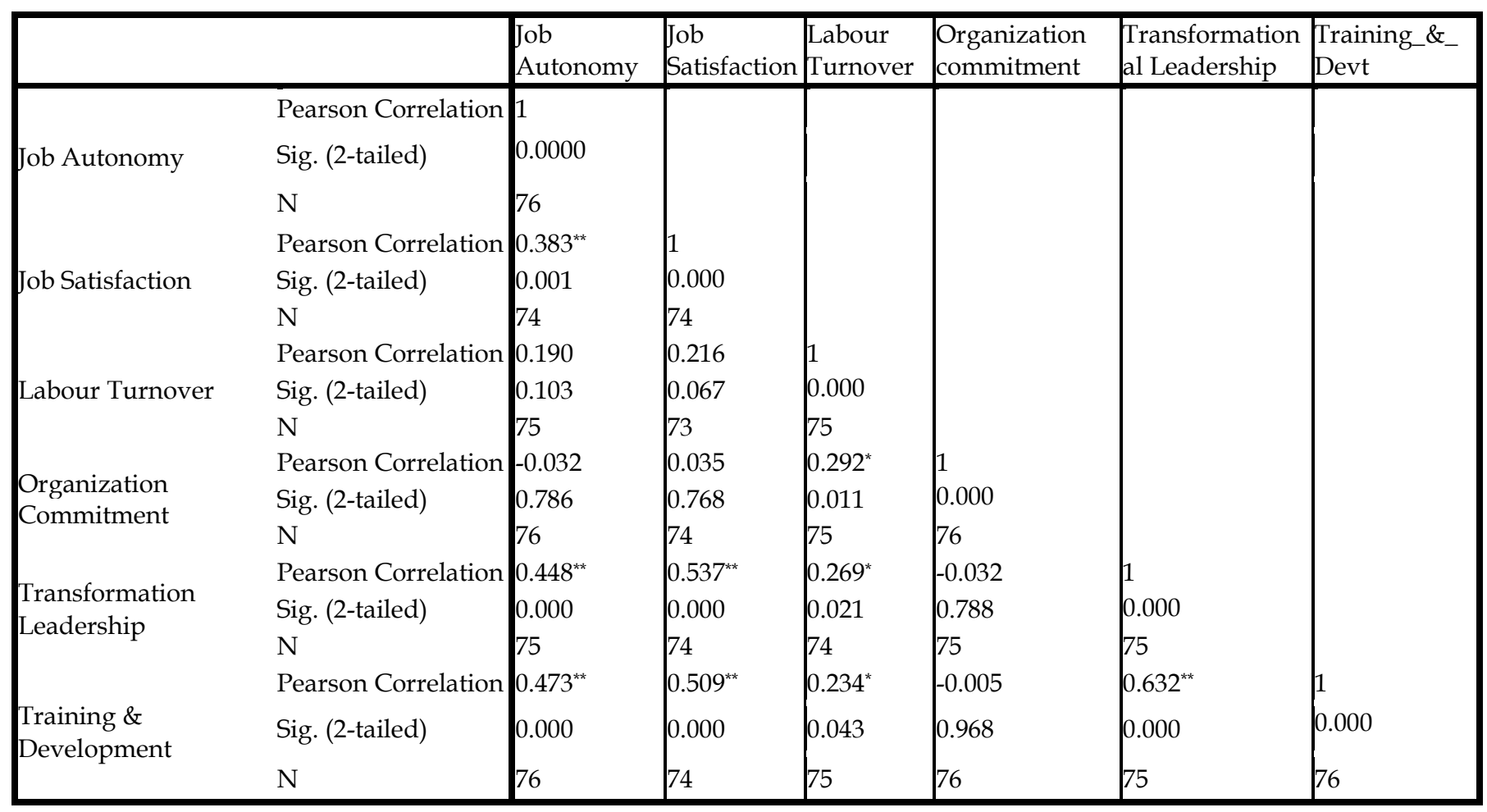

Correlation analysis with the main variables (Table 1) indicated significant and strong positive relationship among the study variables with correlation co-efficient ranging from $r=0.383(p>$ $0.01)$ to $r=0.632(p>0.01)$. The correlation findings are consistent with other reported findings (Monari, 2013).

\section{Hypothesis One}

\section{Job Autonomy and Organization Performance}

Results of regression analysis for the independent variable, job autonomy explained $4.8 \%$ of all the variation in organization performance while other factors explained $95.2 \%$ of the variation in organization performance of the SMEs in Mombasa
County. Results also indicated that job autonomy did not influence organization performance of the SMEs in Mombasa County.

Results of ANOVA test indicated at least one of the independent variable, job autonomy did not significantly influence organization performance $(\mathrm{df}=75 ; \mathrm{f}=3.761 ; \mathrm{p}=0.056)$. That is, there was no significant relationship between the independent variable, job autonomy and organization performance of the SMEs in Mombasa County.

More results indicated job autonomy did not significantly influence organization performance of the SMEs in Mombasa County. This was because for every $14.6 \%$ in job autonomy, organization 
performance of the SMEs did not significantly change $(p=0.056)$.

Therefore, job autonomy did not have a significant impact on organization performance. This model can be summarized by the following equation:

$$
y_{i}=3.410+0.146 x_{1} \ldots \ldots \ldots \text { (i) }
$$

Where $y_{i}$ is the organisation performance and $x_{1}$ is the job autonomy.

Since the results of regression analysis indicated no significant relationship in job autonomy with organization performance, this revealed that most of the SMEs in Mombasa County have not embraced the concept of giving employees autonomy yet it contributes a lot in terms of innovation and creativity.

Hypothesis Two

\section{Transformational Leadership and Organization Performance}

Regression results for transformational leadership explained $10.7 \%$ of all the variation in organisation performance while other factors explained $89.3 \%$ of the variation in organisation performance of the SMEs in Mombasa County. Therefore, it can be concluded that transformational leadership influenced organisation performance of the SMEs in Mombasa County to some extent. The results signify that when leaders are visionary the organization benefits, this is because they influence and inspire the workforce.

Results of ANOVA test indicated that transformation leadership significantly influenced the organisation performance $(\mathrm{df}=74 ; \mathrm{f}=8.719 ; \mathrm{p}$ $=0.004$ ). That is, there was a significant relationship between the independent variable, transformation leadership and organisation performance of the SMEs in Mombasa County.

More results showed that transformational leadership significantly influenced the organisation performance. This is because for every $26.8 \%$ in transformation leadership, organisation performance significantly changed $(\mathrm{p}=0.004)$. Therefore, transformation leadership had a significant impact on organisation performance of the SMEs in Mombasa County. This model can be summarized by the following equation:

$$
y_{i}=2.938+0.268 x_{1}
$$

Where $y_{i}$ is the organisation performance and $x_{1}$ is the transformation leadership.

These results signify that transformational leadership played a key role in running of SMEs. The leader has to influence and inspire the workforce to achieve significant results.

\section{Hypothesis Three}

\section{Training and Development and Organization Performance}

Results of the regression analysis for training and development explained $9.7 \%$ of all the variation in organisation performance while other factors explained $90.3 \%$ of the variation in organisation performance. Therefore, training and development influenced organisation performance of SMEs in Mombasa County. Training and development of staff plays a key role in acquisition of skills, knowledge and enhancing abilities. Where there is development the employees have a clear path of career growth, this contributes to their motivation. When employees are motivated they are positive and it enhances their performance

Results of ANOVA test showed that at least one of the independent variable, training and development significantly influenced the organisation performance $(\mathrm{df}=75 ; \mathrm{f}=7.951 ; \mathrm{p}=$ 0.006). That is, there was a significant relationship between the independent variable, training and development and organisation performance of the SMEs in Mombasa County.

More results showed training and development significantly influenced organisation performance. This is because for every $24.7 \%$ in training and development, organisation performance significantly changed $(\mathrm{p}=0.006)$. Therefore, training and development had a significant impact on organisation performance. This model can be summarized by the following equation:

$$
y_{i}=2.997+0.247 x_{1}
$$


Where $y_{i}$ is the organisation performance and $x_{1}$ is the training and development.

\section{Discussion}

Findings from the current study reveal that there is positive relationship between employee engagement and organization performance. Transformational leadership and training and development were found to influence performance. This signifies that to survive in this competitive environment, effective practices and policies on employee engagement is a key strategic task for SMEs. It has been widely acknowledged that effective engagement practices are significant in contributing to organization's objective (Mukerjee, 2014). Baik (2016) showed that managers who are concerned with employee well-being reap results such as job satisfaction, low turnover and employee commitment. When employees are engaged they are able to utilize their competencies to the maximum and this leads to job satisfaction (Armstrong, 2010). This is in line with resource based theory where the competencies of these employees are non-substitutable and rare hence enables the organization to achieve its objectives.

Job autonomy was found not to be significant in the current study. This could probably be attributed to the fact that most SMEs do not give room for free decision making mechanism, the manager makes most of the decision. Further the manager puts tight controls where employees cannot freely perform their duties as they wish. These can affect motivation levels of employees which in turn affects performance of the entire organization. As such, SMEs need to embrace job autonomy as a positive human resource practice which can lead to employees being engaged.

Training and development were found to influence performance of SMEs. When employees feel there are opportunities for growth they will be motivated, and they are likely to perform better leading to enhanced organization performance (Barney, 1991; Lee, 2017). Training and development were found to play an influential role in motivating employees to exhibit favorable attitudes and behaviors which are required to support strategies which can give SMEs competitive advantage. When SMEs develop services and products they require employees that are innovative, creative, risky takers, and flexible; and these can only be achieved if the firms embrace effective employee engagement practices. Effective employee engagement practices reduce labour turnover and leads to job satisfaction as it can be seen from the findings of this current study. Employees are able to generate new ideas, treat customers well and are committed to the organization growth. From the findings it can be concluded that if SMEs embrace transformational leadership where they share the vision and mission of the organization, inspire and train the staff then they will be satisfied and committed to their jobs. This will lead to low turnover and increased performance. Thus it can be concluded from the findings of this current study that engagement of employees affect performance of SMEs in Mombasa County.

Training and development helps the employees to master their skills, knowledge and ability. When there are opportunities for career development and growth employees are motivated which in turn will lead to better performance. Transformational leadership is an opportunity to fit the employee with the organization culture, hence high level adherence to training and development practices is critical. The results offer suggestions to SMEs operators that employee engagement practices need to be embraced in totality especially involving employees in decision making process. Disengaged employees is a major challenge to all organizations, for they work against the interests of the organization. Secondly, an organization can incur costs, underperform and create widespread dissatisfaction reaching even customers.

Implications for policy and practice the current study showed that SMEs have not fully embraced employee engagement concept. Policies and practices should be formulated to support sustainable growth of SMEs in order to continue to create opportunities, wealth creation and improve the economy as a whole. SMEs today should also embrace human resource practices which will lead to enhanced performance.

\section{Conclusion and Recommendations}

It is clear from the findings that with accurate measure of employee engagement the management can implement strategies on what matters to people at work. Employee engagement produces positive 
results. Measuring employee engagement is of great importance. SMEs have to embrace employee engagement practices in order to survive and be successful. When employees see that their employer trust and value their contributions they show positive attitude and it provokes feelings of obligation in the employee. Engagement should be integrated into the human resource system and practices.

The current study recommends that SMEs should understand the philosophy behind employee engagement; they should strive to have engaged employees in their jobs so as to maximize their effectiveness. There is need to create a work environment that encourages employee engagement in order to increase performance and be competitive. The data in this study was crosssectional which looked at one point in time, a longitudinal study need to be undertaken for indepth analysis. Also this study was limited to SMEs in Mombasa County, it is recommended that a similar study be conducted to include the whole of Kenya coast region and compares with other regions and counties in Kenya. Future studies could be carried out with larger sample size which would improve generality of the findings. More studies can be carried to find out why job autonomy was not significant on organization performance.

\section{References}

Adnan R. \& Mubarak H. (2010). Role of transformational and transactional leadership on job satisfaction and career satisfaction. Business and Economic Horizons, Praque Development Centre Vol (1) 1

African Business Review of Business \& Technology (2014). SMEs Are Growing Kenya's Economy. Alan Charles Publishing, London

African Business Review of Business \& Technology (2017). SMEs Are Growing Kenya's Economy. Alan Charles Publishing, London

Akram A., Ali, M. \& Hassa, M. (2013). Impact of Job Autonomy of Management. Journal of Management Science and Business Research. 3(1): 31-44.

Allen, N.J. \& Meyer, J.P. (1990). The Measurement and Antecedents of Affective, Continuance and Normative Commitment to the Organization. Journal of Occupational Psychology (63): 1-18

Amoatemaa, A.S. \& Kyeremeh, D.D. (2016). Making Employee Recognition a Tool for Achieving Improved Performance: Implication for Ghanaian Universities. Journal of Education and Practice Vol.7 (34): 46-52

Armstrong, M. (2010). Handbook of Human Resource Management Practice. $10^{\text {th }}$ edition. London: Kogan

Armstrong, M. (2013). How To Manage People. $2^{\text {nd }}$ ed. London: Kogan

Anwar, N \& Shakur, N. (2015). Employee engagement, human resource management practices and competitive advantage: An integrated approach. Journal of Organizational Effectiveness: People and Performance. Vol 5(5): 1-6.

Avolio, B., \& Bass, B. (1995). Individual consideration viewed at multiple levels of analysis: a multi-level framework for examining the diffusion of transformational leadership. The Leadership Quarterly, 6, 199-218

Ayers, K.E. (2006). Engagement is not enough. Integro Leadership Institute LLC.

Baik, A. (2016). Employee Engagement to Organization Culture: A Case Study on SMEs. University Sans Malayasia. 23-26

Barney, J. (1991). Firm Resources and Sustained Competitive Advantage. Journal of Management Vol. 17, No 1, 99-120

Bishop M. \& Crooks S. (2019). HR for Small Business for Dummies

Burns, J. M. (1978). Leadership. New York: Harper \& Row

Cole, G.A. (2002). Personnel and Human Resource Management $\left(5^{\text {th }}\right.$ edition.). Continuum London: NewYork Publishers

Cooper, C.R., \& Schindler, P.S. (2008). Business Research Methods (10 ${ }^{\text {th }}$ edition.). Boston: McGraw-Hill

Dessler, G. (2015). Human Resource Management (14 ${ }^{\text {th }}$ edition). New Delhi, Prentice Hall

Gallup S. (2015). The 2015 Employee Engagement Survey. USA

Guest, D.E. (ed) (2013). 'Employee Engagement: Fashionable Fad or Long-Term Fixture?' in Employee Engagement in Theory and Practice London: Routledge 
Guest, D. (2014). Employee engagement: a skeptical analysis. Journal of Organizational Effectiveness: People and Performance 1(2):141 - 156

Fazna M. \& Zubair, H. (2016). Factors Influencing Employee Engagement: A Study on a Telecommunication Network provider in Maldives. International Journal of Accounting and Business Management Vol. (4)1: 50-60

Hassan, S. \& Shoaib, M. (2014). Measuring the impact of perceived organization support, psychological empowerment and rewards on employees' satisfaction: Testing the mediating impact of employee engagement. World Applied Sciences Journal 30 (5): 652-660

Herzberg, F. (2003). One more time: How do you motivate employees? Harvard Business Review, 81(1), 86

Ibua, M. (2017). Employee Empowerment and Performance of Public Universities in Kenya. Strategic Journal of Business \& Change Management Vol (4): 479-495

Jenatabadi, H.S. (2015). An Overview of Organizational Performance Index: Definitions and Measurements. University of Malaya, Malaysia 7(12): 16196-16212

Kahn, W.A. (1990). Psychological conditions of personal engagement and disengagement at work. Academy of Management Journal, 33(4), 692-724.

Kanter, R.M. (1997). Frontiers of Management. Harvard Business School Press, Boston.

Kaplan, R.S. \& Norton, D.P. (1993). Putting the Balanced Scorecard to Work, Harvard Business Review, September-October: 134147

Kenya National Bureau of Statistics (2016), National Micro and Small Enterprise Baseline Survey 2012, Survey Results, the Kenya National Bureau of Statistics (KNBS) - Kenya: 1-10

Kahn, W.A (1990). 'Psychological conditions of personal engagement and disengagement at work', Academy of Management Journal, 33(4), 692-724

Kombo, D. \& Tromp, L. (2009). Proposal and Thesis Writing; An Introduction. Pauline Publications Africa, Nairobi

Langfred, C.W. \& Moye N.A. (2004). Effects of Task Autonomy on Performance: An Extended Model Considering Motivational,
Informational and Structural Mechanisms. Journal of Applied Psychology 89(6): 934-945

Lee A., Sara W. \& Amy W.T. (2017). Empowering Leadership: A Meta-analytic examination of incremental contribution, mediation, and moderation. Journal of Organizational Behavior. 39(3): 306-325

Mahony \& Kor. (2015) Advancing the Human Capital Perspective on Value Creation by Joining Capabilities and Governance Approaches. Academy of Management 29: 296-308

Monari F. (2013). The Influence of Time Management Tendencies and Organizational Factors on the Relationship between Employee Attributes and Organizational Performance of Universities in Kenya. PhD Thesis. University of Nairobi: 219-2025

Mondy, R.W. (2010). Human Resource Management. Upper Saddle River, New Jersey; 2010, Pearson/Prentice Hall

Mozael, B.M. (2015) Impact of Training and Development Programs on Employee Performance. International Journal of Scientific and Research Publications 5(11): 2250-3153

Mukerjee, K. (2014). Fostering Employee Engagement in Organization. A Conceptual Framework. International Journal of Management Practice 7(2): 160-176

National Economic Survey (2017). Central Bank of Kenya Report of 2017

Hackman, J. R., \& Oldham, G. R. (1976). Motivation through the design of work: Test of a theory. Organizational Behavior \& Human Performance, 16(2), 250-279.

Pfeffer, J. (1998). Seven practices of Successful Organizations. California Management Review 40(2): 96-124

Robbins, S.P (2003). Organizational Behavior Concepts, Controversies, Application. $8^{\text {th }}$ edition, Prentice-hall International. New Jersey, USA

Schaufeli, W.B. (ed) (2013), 'What is Engagement?' in Employee Engagement in Theory and Practice. London: Routledge

Shantz, A., Alfes, K., Truss, C., \& Soane, E. (2013). The role of employee engagement in the relationship between job design and task performance, citizenship and deviant behaviours. The International Journal of 
Human Resource Management 24(13): 26082627

Smith, M.A., \& McCanger, J.S. (2004). Effects of supervisor, 'Big Five' Personality on Subordinate Attitude. Journal of Business and Psychology 18: 17-34

Soane, E.C. (2013). Leadership and Employee Engagement,' in Employee Engagement in Theory and Practice, London: Routledge

Truss, C., Alfes, K., Delbridge, R., Shantz, A. \& Soane, E.C. (eds) (2013b). Introduction in Employee Engagement in Theory and Practice. London: Routledge

Vance, R. (2006). Employee Engagement and Commitment. Society of Human Resources Management -UK

Weiss, H. M. (2002). Deconstructing Job Satisfaction: Separating Evaluations, Beliefs and Affective Experiences. Human Resource Management Review 12(2): 173-194.

Wilson (2010). 2010 Study on the State of Performance Management. World at Work, Total Reward Association 